\title{
Tecnologia de Informação e Desempenho Empresarial no Gerenciamento de seus Projetos: um Estudo de Caso de uma Indústria
}

Information Technology and Business Performance on its Projects Management: a Case Study about a Industry

\author{
Alberto Luiz Albertin* \\ Doutor pela FEA/USP. \\ Professor da FGV-EAESP, São Paulo/SP, Brasil. \\ Rosa Maria de Moura Albertin \\ Doutoranda da FGV-EAESP. \\ Pesquisadora da FGV-EAESP, São Paulo/SP, Brasil.
}

*Endereço: Av. Nove de Julho, 2029, Bela Vista, São Paulo/SP, 01313-902. E-mail: albertin@fgv.br 


\section{ResUMo}

A Tecnologia de Informação [TI] tem sido considerada um dos componentes mais importantes do ambiente empresarial atual, oferecendo grandes oportunidades para as empresas que têm sucesso no aproveitamento dos benefícios oferecidos por este uso no desempenho empresarial. Este trabalho tem como objetivo apresentar a relação entre os benefícios oferecidos pelo uso de TI e o desempenho empresarial, e a sua aplicação no gerenciamento de projetos de TI, por meio de um instrumento específico desenvolvido para este fim. A metodologia utilizada é o estudo de caso numa empresa líder de seu setor, com investimento significativo em TI e que, a partir do estudo, passou a utilizar este instrumento para a avaliação e acompanhamento dos gastos e investimentos nesta tecnologia. O resultado principal é a consolidação deste instrumento para avaliar os gastos e investimentos em TI, e sua incorporação nos processos de gerenciamento de projetos de TI, inclusive após a sua implementação, permitindo concluir que é possível vincular o uso de TI com desempenho empresarial e que este vínculo deve ser a base para a tomada de decisão. A contribuição do trabalho é a identificação dos benefícios oferecidos pela TI, a relação com o desempenho empresarial e a sua aplicação no gerenciamento de projetos TI, brindando subsídios importantes para a sua administração.

Palavras-chave: tecnologia de informação; administração de tecnologia de informação; desempenho empresarial; gerenciamento de projetos de tecnologia de informação.

\section{ABSTRACT}

The Information Technology [IT] has been considered like one of the current managerial environment more important components, offering great opportunities for the companies that have success in the offered benefits utilization for this use. This article has as main objective to present the relationship among the Information Technology utilization effective benefit business performance, and its application on the IT projects management, using a specific structure developed for this purpose. The methodology is case study on a company leader on its industry, with significant IT investment, which adopted this tool to evaluate and control its cost and the investment on this technology. The main result is this structure consolidation as a tool for analysis about cost and investment on IT; and its incorporation on the processes of IT projects management, even after its implementation. These results permit to conclude that it is possible to relate IT utilization with business performance and it should be the basis to decision making. Its contribution is the identification of offered benefits by IT, the relationship with business performance and its impact on IT projects management, offering important subsidies for its administration.

Key words: information technology; information technology management; business performance; information technology project management. 


\section{INTRODUÇÃO}

A Tecnologia de Informação [TI] tem sido considerada um dos componentes mais importantes do ambiente empresarial atual; as organizações brasileiras têm utilizado ampla e intensamente esta tecnologia, tanto em nível estratégico como operacional (Albertin, 2004).

Essa utilização oferece grandes oportunidades para as empresas que têm sucesso no aproveitamento dos benefícios oferecidos por este uso. Ao mesmo tempo, ele também oferece desafios para a administração de TI; as empresas passam a ter grande dependência dele, apresentando particularidades no seu gerenciamento. Neste cenário complexo, um dos desafios mais críticos é identificar o nível de contribuição que esta tecnologia oferece aos resultados das empresas.

Neste ambiente, torna-se imprescindível o conhecimento das cinco dimensões do uso de TI: utilização em si, benefícios oferecidos, contribuição para o desempenho empresarial, governança e administração de TI, e o papel dos executivos, e da relação que existe entre estas dimensões, para que se possa garantir a sua coerência, além do tratamento individual das particularidades de cada uma delas (Albertin \& Albertin, 2005).

Assim, o problema de pesquisa é como estabelecer uma relação entre o uso de TI e seus benefícios oferecidos no desempenho empresarial, relação que possa ser aplicada no gerenciamento de projetos de TI.

Este trabalho tem como objetivo apresentar a relação entre os benefícios oferecidos pelo uso de TI e o desempenho empresarial, e a aplicação desta relação no gerenciamento de projetos de TI, por meio de um instrumento desenvolvido para este fim.

A metodologia utilizada é o estudo de caso numa empresa líder de seu setor, com investimento significativo em TI e que, a partir do estudo, passou a utilizar este instrumento para a avaliação e acompanhamento dos gastos e investimentos nesta tecnologia.

A justificativa deste trabalho baseia-se na certeza de que a oferta de TI e seu aproveitamento amplo e intenso pelas organizações têm sido considerado como realidade nos vários setores da economia e condição básica para as empresas sobreviverem e competirem. 
Algumas das oportunidades oferecidas por este novo ambiente têm-se confirmado, enquanto outras ainda não estão de fato sendo alcançadas, muitas vezes pela administração não adequada da TI nas empresas, o que inclui a relação de sua utilização com o desempenho empresarial. Os administradores têm enfrentado os desafios deste ambiente cada vez mais complexo e que requer um conhecimento mais profundo de suas particularidades e dinâmicas (Albertin, 2004).

A contribuição do trabalho é a identificação dos benefícios oferecidos pela TI, a relação com o desempenho empresarial e a sua aplicação no gerenciamento de projetos de TI. Além da identificação, a apresentação de um instrumento não só de análise e avaliação, mas também de orientação para o tratamento adequado do uso de TI.

\section{Fundamentação TEÓRICA}

A TI pode ser entendida como sendo hardware, software e pessoas envolvidas na obtenção, armazenamento, tratamento, comunicação e disponibilização de informação (Albertin, 2004). Neste trabalho, este conceito amplo de TI será utilizado para possibilitar o entendimento também amplo do seu uso nas organizações.

\section{Dimensões do Uso de Tecnologia de Informação}

$\mathrm{O}$ uso de TI nas empresas deve ser entendido por meio do conhecimento das suas várias dimensões, incluindo o contexto com seus direcionadores, os tipos de uso de TI, o desempenho empresarial, a governança e a administração de TI e o papel dos executivos de negócio e de TI, bem como a relação que existe entre elas (Albertin \& Albertin, 2005). Estas dimensões são identificadas no Modelo das Dimensões do Uso de Tecnologia de Informação em Benefício dos Negócios, apresentado na Figura 1. 


\section{Figura 1: Modelo das Dimensões do Uso de Tecnologia de Informação em Benefício dos Negócios}

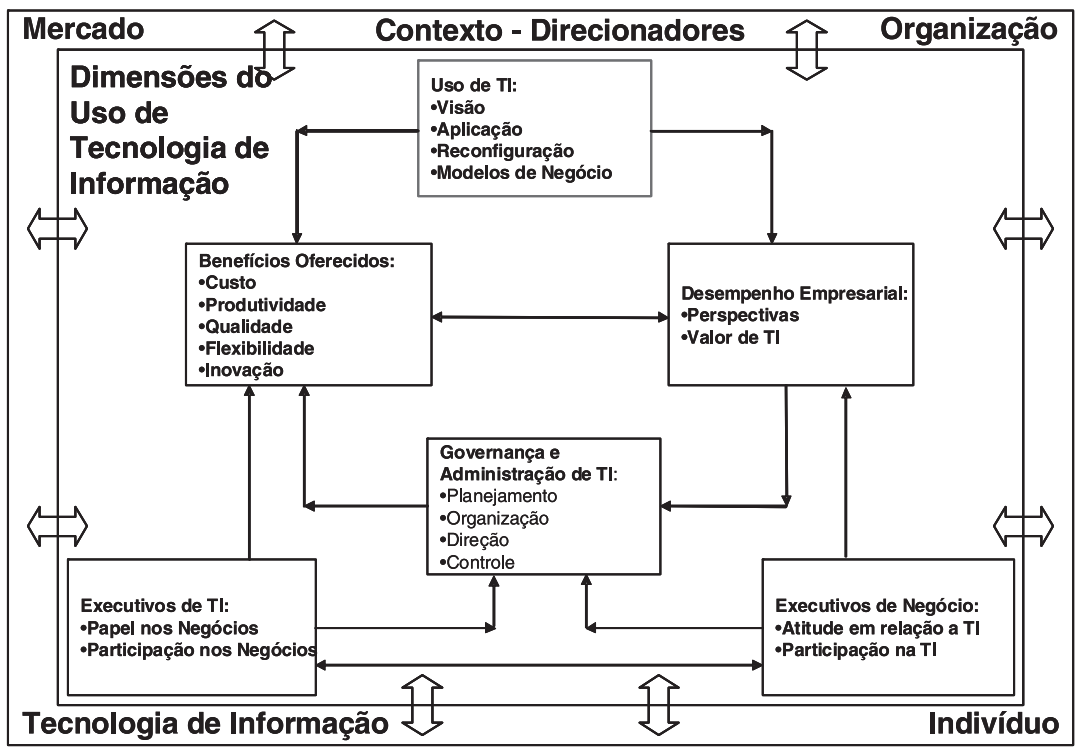

Fonte: Albertin e Albertin (2005, p. 94).

As organizações devem definir as suas diretrizes, estratégias e operacionalização, considerando o contexto em que atuam, aproveitando as oportunidades e vencendo os desafios apresentados. Neste cenário, a TI é um dos componentes organizacionais mais importantes e tem permeado praticamente todas as ações internas e externas.

Desta forma, o uso de TI também deve considerar o contexto, definido neste trabalho pelos direcionadores das respostas organizacionais e do uso de TI, incluindo as pressões de mercado, organizacionais, de indivíduo e da própria tecnologia. $\mathrm{O}$ valor que a TI poderá agregar à organização está diretamente relacionado com a qualidade do estudo destes direcionadores (Amor, 2000; Hackett, 1990; Kanter, 2001; Morton, 1991).

O uso de TI também será determinado pela visão e valor que esta tecnologia tem para a empresa, assim como pelas várias aplicações de TI que estão à disposição das organizações (Weill \& Broadlent, 1998) e que tem níveis diferentes de reconfiguração de negócio (Venkatraman, 1991), dependendo da necessidade definida pelos direcionadores. No nível mais elevado, a TI pode contribuir de forma definitiva para a criação de novos modelos de negócio (Means \& Schneider, 2000; Murphy, 2002; Sampler, 1998; Weill \& Vitale, 2001). 
As organizações dependem de certos requisitos para garantirem seu sucesso que pode ser alcançado com a utilização de TI (Baschab \& Piot, 2003; Slack, Chambers, \& Johnston, 2000; Tardugno, Dipasquale, \& Matthews, 2000). O uso de TI oferece benefícios para os negócios que incluem custo, produtividade, qualidade, flexibilidade e inovação; cada uso tem uma composição própria destes benefícios. O desafio das organizações é determinar, o mais precisamente possível, quais os realmente ofertados e desejados, pois esta identificação será a base para a confirmação destes benefícios no desempenho empresarial.

O desempenho empresarial certamente tem sido afetado pelo uso de TI, porém a maneira como isto ocorre depende da perspectiva usada na relação entre a organização e a TI, que pode ser desde a consideração de TI como simples decorrência das diretrizes organizacionais, até a TI como facilitadora e fornecedora de inovações de negócio. Estas perspectivas determinam o valor que à TI é dado e aquele que se espera do seu uso. O desempenho empresarial inclui aspectos financeiros e não financeiros (Murphy, 2002; Venkatraman, 1989).

A governança de TI pode ser entendida como a autoridade e responsabilidade pelas decisões referentes ao uso de TI. A administração de TI, com seus processos de planejamento, organização, direção e controle, tem como objetivo garantir a realização bem sucedida dos esforços para o uso de TI, desde a sua definição com o alinhamento estratégico, influenciado pelo contexto, até a mensuração dos seus impactos no desempenho empresarial (Albertin \& Albertin, 2005). O gerenciamento de projetos faz parte desta administração.

A administração de TI não deve ser realizada apenas pelos executivos desta área, mas é uma responsabilidade organizacional na qual os executivos de negócio têm participação decisiva no seu sucesso (Schein, 1989).

Os executivos de negócio devem ter uma atitude em relação com a TI adequada ao que se espera desta tecnologia, de forma crítica e realista, mas também permitindo que as suas inovações sejam aproveitadas pelas organizações como parte de sua estratégia e operacionalização. Para tanto, eles devem participar ativa e decisivamente na administração de TI em conjunto com os executivos desta área.

Os executivos de TI devem ter um papel ativo e decisivo nos negócios, assim como os demais executivos, mas com a particularidade de serem de uma área que permeia todas as demais e tem características próprias de inovação. Eles devem participar nos negócios e não só permitir, mas incentivar a participação dos demais executivos.

As dimensões do uso de TI e suas relações produzem efeitos internos e externos 
nas organizações, o que significa que elas também influenciam o contexto e seus direcionadores, alterando-os e sendo alteradas por eles.

O foco deste trabalho está nas dimensões de benefícios oferecidos e sua relação com o desempenho empresarial, e na aplicação desta relação no gerenciamento de projetos de TI, o que faz parte da administração de TI. Porém não é possível analisar a relação entre estas dimensões sem considerar as demais, ou seja, o uso de TI e a atitude dos executivos de TI e de negócio na sua percepção sobre estas dimensões.

\section{Benefícios Oferecidos pelo Uso de Tecnologia de Informação e o Desempenho Empresarial}

A área de TI está sob crescente pressão para tornar evidente o seu entendimento sobre o que constitui o valor de negócio que ela oferece e demonstrar a contribuição oferecida por um investimento em TI antes do investimento ser feito. Os executivos de TI precisam ter estrutura para analisar esses investimentos e ter métricas para definir seu sucesso (Towell, 1999).

Os investimentos em TI apresentam fundamentos diferentes dos demais investimentos realizados pelas organizações. Após cuidadosa análise do investimento e seus benefícios antecipáveis, a decisão é tomada com base nesta comparação. Porém, em TI, estes aspectos não são tão facilmente identificados (Mahmood \& Szewczak, 1999a).

Os estudos sobre o uso de TI não apresentam consenso sobre o melhor enfoque, medidas ou nível de análise a serem utilizados para medir o valor de negócio dos investimentos em TI. A maioria dos estudos foi baseada em muitas disciplinas, por exemplo, nos aspectos microeconômicos, econômicos e financeiros; e foram usadas várias teorias, como a teoria da firma, valor da informação e valor do tempo do dinheiro; e o emprego de muitas variáveis dependentes desde índices financeiros, até a satisfação. A maioria dos modelos usados nas pesquisas assume a relação direta entre tecnologia e algumas medidas de desempenho, e esta visão é denominada de modelo básico e inclui investimento e desempenho organizacional (McKeen, Smith, \& Parent, 1999).

McKeen e Smith (1993) identificaram que o orçamento de TI é utilizado quase exclusivamente como medida do nível de informatização. Esta situação acaba negligenciando um importante aspecto de TI: seu desenvolvimento. Nesta visão, em que a TI é desenvolvida pelo esforço das pessoas, não é adequado analisar o impacto no desempenho sem considerar as pessoas. Somente avaliando os dois recursos, pessoas e TI no desenvolvimento, é possível obter o valor efetivo de TI. 
A noção de efetividade de conversão é explorada por Markus e Soh (1993); eles argumentam que existem dois grupos de fatores que determinam se o valor de TI é obtido ou não. O primeiro refere-se aos fatores estruturais que determinam as diferenças entre empresas, na sua habilidade de obter benefícios a partir dos gastos com TI, como, por exemplo, tamanho, setor, posição competitiva, entre outros. O segundo refere-se aos processos gerenciais internos, que incluem formular estratégia de TI, selecionar a estrutura organizacional para executar essa estratégia, desenvolver a aplicação de TI adequada e gerenciar projetos de desenvolvimento de aplicações de TI efetivamente.

O modelo definido por Trice e Treacy (1986), proposto antes dos modelos apresentados e já comentados, surgiu da investigação sobre medidas de efetividade de TI que sempre envolve medidas de utilização de TI. Neste modelo, a utilização de TI deve ser uma variável interveniente entre investimento de TI e desempenho empresarial, uma vez que TI não pode afetar o desempenho, se não for utilizada de alguma forma. As relações entre a utilização de TI e o desempenho empresarial são complexas, sendo impossível traçar uma relação teórica clara entre TI e o desempenho empresarial, sem incluir a utilização.

Devaraj e Kohli (2002) argumentam que o custo e o investimento em TI serão refletidos no desempenho empresarial por meio do processo de uso de TI, refletido nos produtos e serviços de TI, o que implicará impacto deste uso, que finalmente afetará o resultado empresarial.

Uma possível síntese dos modelos desenvolvidos considera que o investimento em TI deve ser considerado como cadeia de processos de transformação, antes de resultar em algum desempenho empresarial. Esta cadeia inclui governança, investimento, desenvolvimento, utilização de TI e, finalmente, desempenho empresarial. Este modelo sintetizado seria aplicável em diferentes níveis de análise: sistema de informação específico, organização como um todo, e setor da economia.

Este enfoque de análise permite que sejam elaboradas proposições (McKeen et al., 1999), como por exemplo:

. com o foco no nível da organização, deve ser possível capturar o efeito do investimento total no desempenho da organização;

- a governança de TI no nível de organização deve ser determinável, estabelecendo o nível de controle exercido sobre ativos de informação; e

. o nível em que os objetivos organizacionais ou de governança são atingidos por um investimento em TI pode também constituir um indicador apropriado do desempenho organizacional. 
Mahmood e Szewczak (1999b) concluem seus estudos sobre retorno de investimento em TI com proposições e diretrizes. Alguns exemplos de proposições e diretrizes vêm a seguir.

. Proposições.

- A natureza multidimensional do retorno dos investimentos em TI requer que diferentes categorias de medidas sejam criadas para tratar as várias dimensões: quantitativas, qualitativas e orientação de processos.

\section{. Diretrizes.}

- Adotar uma visão multidimensional da mediação do retorno de investimentos em TI.

- Medir o retorno de investimentos em TI em vários níveis da organização.

Os vários autores concordam que analisar os aspectos econômicos dos investimentos em TI é difícil e complexo, sendo que as técnicas financeiras e quantitativas não bastam para esta análise. Muitas vezes, o enfoque intuitivo é empregado, permitindo que o otimismo ou ceticismo sejam utilizados, colocando em risco o sucesso da organização, seja pelo investimento indevido ou pela não realização de um investimento necessário (Christopher, 2000).

Albertin e Albertin (2005) definem que o aproveitamento dos benefícios do uso de TI no desempenho empresarial se dará por meio dos processos e estratégias que são afetados e apoiados por TI e que irão compor este desempenho. O uso de TI, tanto como infra-estrutura como suas aplicações em processos organizacionais, oferece os benefícios de custo, produtividade, qualidade, flexibilidade e inovação que deverão ser mensurados nos negócios, formando assim a Estrutura de Benefícios de Tecnologia de Informação no Desempenho Empresarial, conforme apresenta a Figura 2.

Os benefícios do uso de TI devem ter métricas que os vinculem com o desempenho empresarial e que permitam a sua justificativa e avaliação constante. Estas métricas formam os indicadores que podem estabelecer a relação direta ou indireta entre o uso de TI e o desempenho empresarial.

Esta relação, então, apresentará a contribuição dos gastos e investimentos de TI, porém sempre será alcançada e determinada em função das variáveis que a afetam: variáveis de mercado, tecnológicas, organizacionais e de indivíduo. Estas variáveis representam a interferência que os direcionadores têm no desempenho empresarial e o que recebem deste desempenho. 


\section{Figura 2: Estrutura de Benefícios do Uso de Tecnologia de Informação no Desempenho Empresarial}

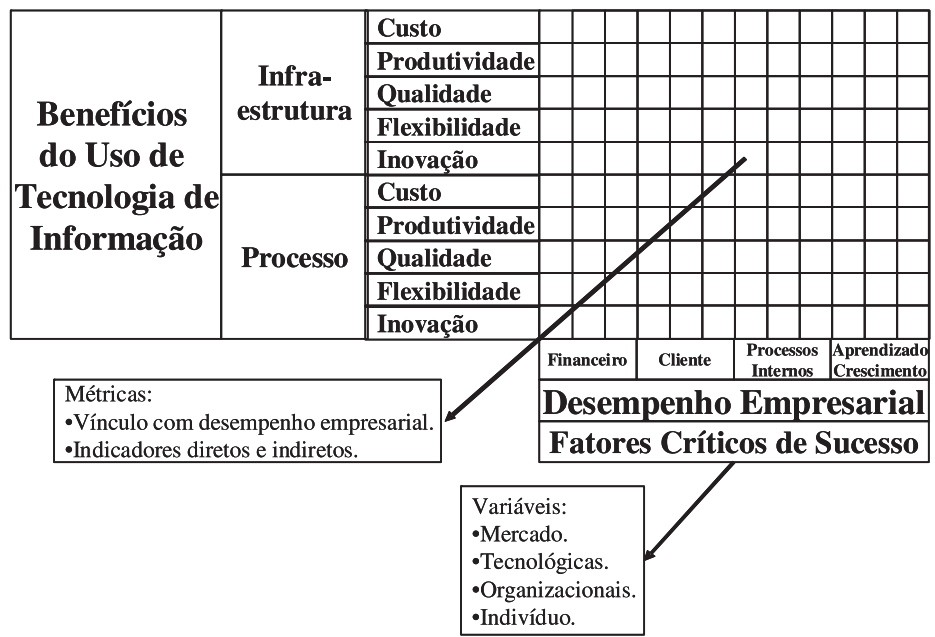

Fonte: Albertin e Albertin (2005, p. 101).

O desenvolvimento deste instrumento utilizou os conceitos de Balanced Scorecard (Kaplan \& Norton, 1996), que considera quatro perspectivas: financeira, cliente, processos internos e aprendizado e crescimento; elas são entendidas como maneira bastante adequada e abrangente de analisar o desempenho empresarial. O enfoque de fator crítico de sucesso colabora para um efetivo controle estratégico (Veen-Dirks \& Wijn, 2002). Esta utilização atende às proposições e diretrizes mencionadas anteriormente neste trabalho.

\section{Gerenciamento de Projetos de Tecnologia de Informação}

Os esforços organizacionais para a assimilação e utilização de TI são realizados na forma de projetos de TI. Esta resposta à necessidade da organização tem como característica a existência de um objetivo predeterminado, com qualidade, prazo, orçamento, condições ambientais e satisfação dos envolvidos, incertezas, complexidade e urgências.

O Gerenciamento de Projetos é a aplicação de conhecimento, habilidades, ferramentas e técnicas, para atender ou exceder as expectativas dos requisitos do solicitante de um projeto (Project Management Institute [PMI], 1998).

As organizações, num esforço comumente denominado de identificação de necessidades, a partir de uma análise de contexto, realizada de forma proativa ou reativa, identifica suas necessidades de solução de um possível problema ou do 
aproveitamento de determinada oportunidade. Estas necessidades são então analisadas e, se aprovadas, devem tornar-se projetos que a organização irá desenvolver.

Os projetos podem ser divididos em fases que compreendem desde a conceituação de um problema ou oportunidade, mediante a análise da situação atual, até a entrega da solução ou produto desenvolvido durante o projeto e a liberação dos recursos.

Segundo Adams e Barndt (1983), e King e Cleland (1983), o conjunto destas fases é denominado de ciclo de vida de projeto; o ciclo de vida genérico é considerado como tendo quatro fases: Conceituação, Estruturação, Execução e Terminal; a denominação das fases pode variar de autor para autor e alguns projetos podem ter estas fases divididas em outras.

Como definido por Pinto e Slevin (1988), Conceituação se refere ao ponto em que uma necessidade estratégica é reconhecida pela organização. Tipicamente, as metas e alternativas preliminares do projeto são estabelecidas, juntamente com a disponibilidade de recursos para alcançar estas metas.

Na Estruturação, também denominada de fase de Planejamento, é estabelecido um conjunto mais formal de planos, que visam garantir que as metas inicialmente desenvolvidas sejam alcançadas. Algumas das funções de planejamento são utilizadas para identificar os recursos necessários, o orçamento e a alocação das atividades.

Na Execução, o trabalho do projeto é realmente desenvolvido. Os materiais e recursos são obtidos e transformados nos resultados desejados do projeto. Durante esta fase, a capacidade de desempenho é continuamente avaliada para garantir o desempenho do projeto, conforme havia sido planejado.

Na Terminal, uma vez que o projeto foi completado, a equipe de projeto é liberada, e o pessoal é alocado em novas responsabilidades, recursos que foram alocados no projeto são liberados de volta para a organização e o resultado do projeto, seu produto ou serviço transferem-se para seu usuário.

Cabe mencionar que as fases do ciclo de vida de projetos recebem denominações diferentes, dependendo do autor, e que a sua curva e aplicação dependem do tipo de projeto e aspecto a ser explorado. Para este trabalho, considera-se que os projetos têm uma fase de anteprojeto na qual, com base no contexto interno e externo, se identifica uma necessidade de resolução de algum problema ou de aproveitamento de uma oportunidade de negócio, tanto interna como externamente. Após esta fase inicial, com a aprovação da alta gerência para que 
se inicie este esforço organizacional, seguem as fases de conceituação, estruturação, execução e terminal. Com a implementação do uso de TI, inicia-se a fase de acompanhamento deste uso, tendo como base sua contribuição para o desempenho empresarial e os seus custos.

\section{Desenvolvimento Teórico}

Os projetos devem obedecer a um ciclo de acompanhamento e controle que se inicia com a sua aprovação em nível corporativo e de projeto, e uma avaliação seguida de decisão gerencial em cada ciclo de desenvolvimento, composto pela realização de atividades segundo os pontos de revisão estabelecidos (Kerzner, 1995; Remenyi, Money, \& Sherwood-Smith, 2000). Este enfoque pressupõe a necessidade do uso de algum instrumento que sirva de base para este tipo de tomada de decisão, vinculando o projeto às estratégias e metas corporativas.

Assim, este estudo foi baseado em quatro proposições:

Proposição 1: O uso de TI, expressado pelo seu gasto e investimento, tem vínculo com o desempenho empresarial.

Proposição 2: O estabelecimento deste vínculo permite a criação de uma visão comum do uso de TI.

Proposição 3: Os vínculos do uso de TI com o desempenho empresarial devem servir para a análise de investimento nesta tecnologia.

Proposição 4: Os vínculos do uso de TI com o desempenho empresarial devem ser estabelecidos e utilizados no gerenciamento de projetos de TI.

\section{Método de Pesquisa}

O método utilizado na pesquisa apresentada neste trabalho é o de estudo de caso único (Yin, 1994). O problema de pesquisa pode ser assim resumido: como estabelecer uma relação entre o uso de TI e seus benefícios oferecidos com o desempenho empresarial, que possa ser aplicada no gerenciamento de projetos de TI? 


\section{Estudo de Caso}

A escolha do estudo de caso baseou-se na convicção de que este é trabalho exploratório, abrangente e complexo (Bonoma, 1985), e que requer contextualização e aprofundamento (Lazzarini, 1995). Além de ser uma área com poucos estudos prévios e sua pergunta de pesquisa ser do tipo como (Benbasat, Goldstein, \& Mead, 1987), deve atingir objetivos científicos (Lee, 1989).

A utilização de todos os componentes de um projeto de estudo de caso (Yin, 1994) é suficiente para que o projeto considere as limitações de generalização e os potenciais vieses apontados por Leonard-Barton (1990).

\section{Unidades de Análise, Sujeitos da Pesquisa, Protocolo e Método de Análise dos Dados}

As unidades de análise foram os projetos de TI desenvolvidos pela empresa que serviu de caso. Os sujeitos da pesquisa foram os executivos de TI das áreas de Interfaces Eletrônicas, Desenvolvimento de Sistemas, Infra-estrutura, Interface com Clientes; e os executivos de negócio das áreas de Vendas, Engenharia de Produto, Controladoria e Industrial, além do principal executivo de TI e o executivo ao qual este se reporta.

O protocolo do estudo de caso foi composto com base nas dimensões do uso de TI, em especial na relação entre benefícios oferecidos com o desempenho empresarial, e no ciclo de vida de projetos, o que se explicita a seguir.

- Informações da Empresa: Situação da empresa em relação a seu setor e responsável pelas informações. Receita, investimentos e utilização geral de TI.

. Usos de TI: Principais projetos e serviços de TI.

. Benefícios do Uso de TI: Benefícios declarados na proposta apresentada aos decisores que serviriam de base para:

. aprovação de investimentos;

. tomada de decisão durante a execução dos projetos e avaliação final destes, $\mathrm{e}$

. acompanhamento após implementação projetos. 
- Desempenho da Empresa: Indicadores que a Empresa utiliza para medir e acompanhar seu desempenho.

- Relação entre Uso de TI e Desempenho Empresarial: Vínculos identificados entre os gastos e investimentos em TI e os indicadores de desempenho da Empresa.

\section{. Gerenciamento de projetos de TI}

- Identificação das necessidades: as tomadas de decisão e suas bases para a aprovação dos gastos e investimentos em TI.

- Conceituação do projeto: num primeiro nível de detalhamento, as bases para a tomada de decisão sobre a efetiva aprovação do projeto e para as decisões das suas próximas fases.

. Estruturação do projeto: com o detalhamento do seu planejamento, confirmação das bases utilizadas para a sua aprovação e para o gerenciamento da sua execução e possíveis mudanças no projeto.

- Execução do projeto: os processos e as bases para o gerenciamento de projeto em relação ao seu impacto no desempenho empresarial, em especial para os casos de mudanças necessárias ou solicitadas.

. Terminal do projeto: bases para a avaliação final e encerramento do projeto.

- Acompanhamento do uso de TI: processo de acompanhamento e tomada de decisão em relação aos impactos que o uso de TI tem no desempenho empresarial.

A Estrutura de Benefícios de Tecnologia de Informação no Desempenho Empresarial, apresentada na Figura 2, serviu de protocolo geral para este estudo. Este protocolo geral trata três aspectos do protocolo da pesquisa e serviu como instrumento para obtenção das informações, sua estruturação e sua utilização no gerenciamento de projetos.

As dimensões estudadas neste trabalho, tanto na conceituação, identificação e elaboração, como na sua análise e avaliação, foram abordadas em entrevistas com os principais executivos de negócio e de TI, em encontros separados ou não, visando obter a percepção de cada área em relação aos temas envolvidos. Nas entrevistas, foi utilizado o protocolo e preenchida a Estrutura.

A análise dos dados utilizou a técnica de análise de conteúdo, incluindo procedimentos de categorização, síntese, procura por padrões e identificação 
de aspectos significativos para o entendimento do tema (Bardin, 2004; Schiffrin, 2001; Wodak, 2001; Yin, 1994). As entrevistas foram gravadas e transcritas, e as respostas foram agrupadas de acordo com os grupos de informações do protocolo, por meio de tabela com os grupos e as informações obtidas. A partir desta estruturação, foi realizada a análise de similaridade de respostas e exemplos citados, por meio de análise de conteúdo, para o entendimento da relação do uso de TI com o desempenho empresarial e de sua utilização no gerenciamento de projetos de TI. Um dos projetos estudados serviu como piloto da pesquisa.

\section{Seleção e o Estudo do Caso}

A empresa utilizada como caso é do setor industrial, uma das líderes de seu ramo. A identificação da empresa não será feita por motivos de sigilo requerido pelos seus responsáveis. Porém nenhuma informação importante para a análise do caso será omitida. Neste relatório, iremos denominar de Empresa o caso estudado.

A Empresa teve faturamento superior a R \$ 2 bilhões no ano de 2004, distribuídos em 7 plantas industriais, gastou e investiu mais de $1,5 \%$ de seu faturamento líquido em TI durante o ano de 2004.

O estudo do caso foi realizado entre outubro de 2004 e setembro de 2005, e teve basicamente três etapas. A etapa inicial foi analisar todos os documentos preparados e utilizados nas fases de aprovação e execução dos projetos de uso de TI e de seus serviços, e por meio da participação como pesquisador externo das reuniões do Comitê de Investimento da Empresa e dos demais órgãos que atuam no gerenciamento dos projetos de TI e do acompanhamento do uso de TI.

Na segunda etapa, foram analisados quatro projetos prioritários de uso de TI e de serviços nesta área, visando ao entendimento da situação atual por meio do estudo de documentos, em especial da análise de investimento, e entrevistas com os responsáveis pelas áreas de negócio envolvidas e pela área de TI para obter as suas visões sobre o projeto, a fim de identificar o grau de similaridade entre as visões.

Para estes mesmos projetos e serviços foi utilizada a Estrutura de Benefícios de Tecnologia de Informação no Desempenho Empresarial, visando capturar as visões com uma base formal e comum para todos os envolvidos e também realizar a comprovação de sua validade como instrumento de administração de TI, tanto para a identificação dos vínculos dos gastos e investimentos em TI com o desempenho empresarial, como 
para a criação de uma visão comum e uma base formal para a aprovação dos investimentos em TI, para o gerenciamento dos projetos de TI e para o acompanhamento dos gastos com TI.

$\mathrm{Na}$ terceira fase, foram acompanhados estes projetos e serviços no seu desenvolvimento, em especial na utilização da Estrutura, incluindo o estudo dos documentos de análise de investimentos originais e sua comparação com os resultados da aplicação da Estrutura; a identificação, comparação e discussão das visões dos envolvidos com cada projeto ou serviço com base na Estrutura preenchida; análise dos documentos e depoimentos dos participantes dos projetos de TI que não tinham acesso à Estrutura e a comparação das decisões tomadas com aquelas possíveis com a aplicação deste instrumento; e estudo dos critérios de acompanhamento dos gastos de TI antes e após a utilização da Estrutura.

A seguir são apresentados os projetos e serviços analisados, e a estratégia de análise para cada um.

\section{Projeto de Automação de Força de Vendas}

Este projeto teve como objetivo implementar o sistema de colocação de pedidos e consulta de informações dos clientes em aplicações para meios eletrônicos com acesso à Internet.

A análise deste projeto foi realizada primeiro em separado com a área de TI e, posteriormente, também em separado, com a área de Negócio. O estudo também utilizou as informações disponíveis no documento específico para análise de projetos de TI. A revisão final da planilha da Estrutura foi feita pela área de TI.

\section{Projeto de Sistema de Gerenciamento de Projetos}

Este projeto teve como finalidade implementar ferramentas de sistemas de informações para o gerenciamento integrado de projetos. A análise deste projeto foi realizada em conjunto pelas áreas de TI e de negócio.

\section{Serviço de Armazenamento de Dados}

Este projeto teve como objetivo implementar o serviço de uso de meios eletrônicos específicos de terceiros para o armazenamento e gerenciamento de dados. A análise deste projeto foi realizada somente pela área de TI. 


\section{Serviço de Análise de Negócios}

Este serviço tem como finalidade apoiar as áreas de negócio para a definição de requisitos de TI, identificação de soluções de TI e suporte à utilização eficiente dos recursos de TI. A análise deste projeto foi realizada somente pela área de TI. Este projeto serviu como piloto do estudo.

\section{Benefícios do Uso de Tecnologia de Informação no Desempenho Empresarial - Caso da Empresa}

A Empresa tem investimentos significativos em TI, segundo sua comparação com as demais empresas de seu setor. Porém a percepção dos principais executivos é que estes investimentos são aprovados sem uma base consistente que os vincule aos resultados finais da empresa. Esta situação cria uma razoável pressão sobre a área de TI e todos os projetos apresentados para avaliação, que acabam sendo aprovados pela influência da área de negócio envolvida ou da própria área de TI.

O processo de solicitação de investimento em TI inicia-se com a identificação de necessidade de uso de TI e da aprovação inicial para a alocação de recursos e preparação do início do projeto de uso desta tecnologia. A identificação da necessidade pode ser realizada em separado ou em conjunto pelas áreas de negócio e área de TI.

Uma vez realizada esta identificação e seu compartilhamento entre as áreas de negócio e de TI, elabora-se um documento de análise de investimento que servirá de base para que um comitê organizacional discuta e delibere sobre a conveniência ou não de sua aprovação. Este documento apresenta a descrição geral da necessidade identificada e os principais dados sobre os custos envolvidos e os benefícios esperados. Estas informações são analisadas por meio de cálculos de retorno sobre investimento [ROI] e declarações de premissas, sem um efetivo vínculo com os indicadores de desempenho da Empresa. Este documento pode ser elaborado diretamente pela área de TI ou em conjunto com a área de negócio envolvida.

Após a aprovação do projeto pelo comitê, as áreas envolvidas iniciam as fases de conceituação, estruturação, execução e finalização do projeto; na maioria das vezes, o documento de análise de investimento não é atualizado ou mesmo serve de base para as decisões sobre mudanças do projeto durante o seu desenvolvimento, ou ainda no acompanhamento, após a finalização do projeto. 
Esta situação permite que sejam criadas visões diferentes do mesmo projeto e que não haja uma base formal de vínculo entre o investimento em TI e os indicadores de desempenho da Empresa, que utiliza o Balanced Score Card [BSC]. Desta forma, o gerenciamento dos projetos de TI torna-se dependente da capacidade de influência do solicitante ou proponente do projeto; a Empresa não consegue estabelecer um critério claro e transparente sobre impacto dos benefícios do uso de TI no desempenho empresarial.

A análise do projeto de Automação de Força de Vendas permitiu identificar que as visões preliminares da área de Vendas e da área de TI em relação ao projeto eram distintas. A utilização da Estrutura neste projeto facilitou que fosse criada uma visão comum e mais abrangente do projeto.

A análise conjunta do projeto de Sistema de Gerenciamento de Projetos permitiu identificar que a visão comum das áreas de Engenharia e de TI em relação ao projeto foi sendo aprimorada com o estudo e a utilização da Estrutura, tornandoa mais abrangente.

A análise do projeto de Armazenamento de Dados confirmou que este tipo de projeto permanece apenas com a visão da área de TI pela falta de interlocutores, uma vez que é visto como projeto exclusivo da área de TI.

A análise do serviço de Análise de Negócios identificou que este tipo de serviço permanece apenas com a visão da área de TI, uma vez que foi criado por iniciativa desta área e é tido como de sua responsabilidade.

\section{Consolidação dos Projetos}

Os projetos e serviços de TI foram consolidados em nível de processo, área e corporativo, por meio da Estrutura, para permitir análises nestes três níveis. Com base nos projetos, infra-estrutura e serviços de TI estudados, a consolidação corporativa demonstrou os vínculos neste nível. A análise desta consolidação foi realizada para facilitar a visualização de sua utilização.

Na consolidação, foram considerados os projetos e serviços de TI analisados, os benefícios oferecidos identificados, a sua proporção reconhecida pelos envolvidos, o vínculo com as perspectivas do BSC da Empresa, o nível deste vínculo e os indicadores a serem afetados com os gastos e investimentos se realizados. A Figura 3 apresenta o resultado final da consolidação de todos os projetos estudados. 


\section{Figura 3: Planilha da Estrutura de Benefícios do Uso de Tecnologia de Informação no Desempenho Empresarial - Consolidado do Caso Empresa}

\begin{tabular}{|c|c|c|c|c|c|}
\hline Aplicação e Infra-estrutura & Benefício Oferecido & Proporcão & BSC & Nível & Indicador \\
\hline Automação da Força de Venda & \multirow[t]{4}{*}{ Custo } & \multirow[t]{4}{*}{$13 \%$} & Financeira & Neg & Margem Líquida \\
\hline & & & Clientes & & \\
\hline \multirow{4}{*}{$\begin{array}{l}\text { Sistema de Gerenciamento de } \\
\text { Projetos } \\
\text { Serviços de Armazenamento de } \\
\text { Dados } \\
\text { Serviço de Análise de Negócio }\end{array}$} & & & Processos Internos & & \\
\hline & & & Aprendizado e Crescimento & & \\
\hline & \multirow{3}{*}{ Produtividade } & \multirow{3}{*}{$33 \%$} & $\begin{array}{l}\text { Financeira } \\
\text { Clientes }\end{array}$ & Neg & \begin{tabular}{|l} 
Valor de Investimento \\
Satisfacão dos Clientes
\end{tabular} \\
\hline & & & Processos Internos & $\begin{array}{l}\text { Neg; } \\
\text { Empresa; TI }\end{array}$ & $\begin{array}{l}\text { Atingimento de metas; } \\
\text { Prazo de proposta; Nível de } \\
\text { serviço; Gastos com TI; } \\
\text { Solicitações atendidas; } \\
\text { Novos gastos }\end{array}$ \\
\hline \multirow{2}{*}{ Investimentos $\quad 2.500 .000,0 \phi$} & & & Aprendizado e Crescimento & Neg; TI & $\begin{array}{l}\text { Competências; } \\
\text { Melhoria de Processo; Cobit }\end{array}$ \\
\hline & \multirow[t]{4}{*}{$0_{0}$ Qualidade } & \multirow[t]{4}{*}{$33 \%$} & Financeira & Neg; TI & $\begin{array}{l}\text { Valor de Investimento; Novos } \\
\text { Investimentos }\end{array}$ \\
\hline \multirow{10}{*}{ Áreas de Negóci } & & & Clientes & Empresa & $\begin{array}{l}\text { Satisfação de clientes; } \\
\text { Qualidade das propostas }\end{array}$ \\
\hline & & & Processos Internos & $\begin{array}{l}\text { Neg; } \\
\text { Empresa }\end{array}$ & $\begin{array}{l}\text { Prazo de propostas; Nível de } \\
\text { servico }\end{array}$ \\
\hline & & & Aprendizado e Crescimento & Neg; TI & $\begin{array}{l}\text { Competências; } \\
\text { Melhoria de Processo; Cobit }\end{array}$ \\
\hline & \multirow[t]{3}{*}{ Flexibilidade } & \multirow[t]{3}{*}{$10 \%$} & $\begin{array}{l}\text { Financeira } \\
\text { Clientes }\end{array}$ & \begin{tabular}{|l|} 
Neg \\
Neg; \\
Empresa
\end{tabular} & $\begin{array}{l}\text { Margem Líquida } \\
\text { Satisfação de clientes; } \\
\text { Qualidade das propostas; } \\
\text { Participacão de mercado }\end{array}$ \\
\hline & & & Processos Internos & $\begin{array}{l}\text { Neg; } \\
\text { Empresa }\end{array}$ & $\begin{array}{l}\text { Atingimento de metas; } \\
\text { Prazo de proposta; Nível de } \\
\text { servico; Gasto com TI }\end{array}$ \\
\hline & & & Aprendizado e Crescimento & $\pi$ & Cobit \\
\hline & \multirow[t]{4}{*}{ Inovação } & \multirow[t]{4}{*}{$13 \%$} & Financeira & $\pi$ & Custos de TI \\
\hline & & & Clientes & Neg & Satisfação de clientes \\
\hline & & & Processos Internos & Empresa & Nivel de servico \\
\hline & & & Aprendizado e Crescimento & $\pi ;$ Neg & $\begin{array}{l}\text { Competências; } \\
\text { Promocões; Cobit; Novos }\end{array}$ \\
\hline
\end{tabular}

Esta planilha foi utilizada como instrumento para a análise e aprovação de investimentos, na fase de identificação de necessidade; para o gerenciamento de projetos, nas suas fases; e no acompanhamento dos gastos após a implementação dos projetos. No caso da Empresa, esta planilha foi utilizada efetivamente como base para as decisões do Comitê de Investimento ou como instrumento para análise de decisões já tomadas.

\section{Conclusões}

Os objetivos do projeto de pesquisa foram atingidos por meio dos resultados obtidos. Os principais resultados relacionados com a relação entre o uso de TI e o desempenho empresarial e a interação destas dimensões com o gerenciamento de projetos de TI são apresentados a seguir, com base nas proposições do estudo.

\section{Proposição 1: O Uso de $\mathrm{TI}$, Expressado pelo seu Gasto e Investimento, Tem Vínculo com o Desempenho Empresarial}

A situação prévia da Empresa em relação às justificativas e análises de investimentos e gastos em TI deixa clara a deficiência na utilização de 
instrumentos que permitam analisá-los de forma confiável, comparando-os com o resultado empresarial. As afirmações dos principais executivos confirmam esta observação.

"Os projetos de TI são apresentados com estudos financeiros de retorno de investimento que parecem consistentes em si, mas com pouca ou nenhuma relação direta com os resultados da empresa que, no fundo, é o que o Comitê de Investimentos entende" (Executivo sênior ao qual o principal executivo de TI responde).

"Todos os projetos têm uma análise de investimento com os procedimentos tradicionais para este fim; mas a análise do Comitê de Investimentos acaba recaindo na discussão de negócio, buscando identificar onde o projeto irá contribuir" (Principal executivo de TI).

Como conclusão geral do estudo, após as análises dos projetos e utilização da Estrutura de Benefícios de Tecnologia de Informação no Desempenho Empresarial, confirmou-se que a relação entre o uso de TI e o desempenho empresarial pode ser identificada, por intermédio dos benefícios esperados, e o seu vínculo pode ser relacionado com indicadores e métricas, guardadas as possíveis restrições. Os executivos demonstraram esta convicção, como se testemunha em seguida.

"Na realidade, esta maneira de expressar a relação dos investimentos em TI com os resultados da empresa é o que sempre tentávamos fazer para viabilizar uma decisão; agora todos estão compromissados com os indicadores de negócio" (Executivo sênior ao qual o principal executivo de TI responde).

"A discussão dos investimentos ficou mais fácil; agora se discute qual é o indicador prioritário e toma-se a decisão, permitindo que seja avaliado o investimento no resultado da empresa" (Principal executivo de TI).

Os principais vínculos identificados foram divididos em três categorias: direto no desempenho empresarial; indireto, com identificação e estabelecimento de algum critério de relação; e baseado em muitas variáveis com maior peso.

Para esta última categoria, os indicadores e métricas de vínculo entre o uso de TI poderão ser intangíveis e apenas indícios. Os estudos indicam que um grupo não desprezível de gastos e investimentos é desta categoria e dependem de decisões estratégicas.

Cabe mencionar que após a conclusão do projeto de pesquisa na Empresa, esta adotou a metodologia e as estruturas descritas como procedimento para análise de investimento e gastos em TI e no acompanhamento do uso desta tecnologia. 
“O vínculo do uso de TI com o desempenho empresarial é similar à relação que a minha área tem com estes indicadores, pois também são como a minha área vai contribuir para eles" (Executivo da área de Vendas).

"Finalmente, temos uma forma estruturada para analisar os investimentos e acompanhar os projetos" (Executivo da área de Projetos).

“Apesar da dificuldade da análise de investimento em infra-estrutura de TI, passamos a ter algo que expressa a relação deste tipo de investimento com a empresa como um todo e não apenas como assunto técnico de TI" (Executivo da área de Infra-estrutura de TI).

"Na minha área, esta visão desta relação de alguma forma já existia, mas dependia de cada área e projeto, pois não era estruturada e formal" (Executivo da área negócio que interage com a Análise de Negócio).

As afirmações dos executivos e o resultado da aplicação do instrumento de análise permitem confirmar a proposição 1, pelo vínculo identificado e expressado entre o uso de TI com o desempenho empresarial.

\section{Proposição 2: O Estabelecimento deste Vínculo Permite a Criação de uma Visão Comum do Uso de TI}

O estudo do projeto de Automação de Força de Vendas com a Estrutura de Benefícios de Tecnologia de Informação no Desempenho Empresarial foi realizado primeiro com a área de TI e depois com as áreas de negócio, e confirmou a diferença das percepções sobre o uso de TI e os benefícios oferecidos, inclusive entre as áreas de negócio.

"Este projeto é mais de TI do que nós, ele atende às inovações tecnologias" (Executivo da área de Vendas).

"Este projeto vai dar um grande impulso na área de Vendas" (Executivo de TI).

O estudo do projeto Sistema de Gerenciamento de Projetos foi realizado em conjunto pelas áreas de TI e de Engenharia, o que permitiu o estabelecimento de uma visão comum do uso de TI por meio da Estrutura.

"Como nossas áreas começaram juntas a discutir o projeto, ficou natural termos uma visão comum" (Executivo da área de Engenharia).

"Nós passamos a entender melhor a posição deles e eles a nossa" (Executivo de TI).

A discussão com as duas áreas permitiu estabelecer uma visão comum sobre o uso de TI, em especial dos projetos estudados. Esta análise levantou outros 
questionamentos referentes às responsabilidades e decisões de TI, que estão relacionados com a governança de TI.

Desta forma, a Estrutura de Benefícios de Tecnologia de Informação no Desempenho Empresarial é instrumento efetivo para o estabelecimento de uma visão comum do uso de TI que deve ser incorporado às práticas de administração de TI.

"Esta estrutura diminui consideravelmente os casos onde as áreas de negócio e a área de TI defendiam de forma diferente um mesmo projeto, muitas vezes com noções diferentes de prioridade" (Executivo sênior ao qual o principal executivo de TI responde).

"Agora de fato podemos ter as áreas de negócio comprometidas com a aprovação dos investimentos e com os próprios projetos" (Principal executivo de TI).

Esta visão comum é essencial para a análise dos investimentos em TI, para o gerenciamento dos projetos de TI e para o acompanhamento dos gastos em TI, sob pena de as decisões serem totalmente afetadas pela percepção do tomador de decisão sem uma base comum e formal que integre as percepções e realidades das áreas envolvidas e de seus participantes.

A visão comum identificada pelas afirmações dos executivos, após o estudo, permite confirmar a proposição 2 .

\section{Proposição 3: Os Vínculos do Uso de TI com o Desempenho Empresarial Devem Servir para a Análise de Investimento nesta Tecnologia}

A Estrutura de Benefícios de Tecnologia de Informação no Desempenho Empresarial se mostrou adequada para a análise dos investimentos em TI, em projetos de aplicações de TI nos processos de negócio, bem como para o acompanhamento da relação dos gastos de TI com o desempenho empresarial, após a implementação dos projetos.

"Esta nova forma de analisar os investimentos permite que o Comitê se preocupe mais em garantir a melhoria dos indicadores de desempenho e tenha um instrumento de analisar os gastos após a entrega dos produtos finais" (Executivo sênior ao qual o principal executivo de TI responde).

A sua incorporação na análise de investimento de TI e na solicitação de serviços de TI permitirá que todos os investimentos e gastos com TI sejam analisados, considerando o ponto exato de contribuição no desempenho empresarial. Esta situação permite que os investimentos possam ser analisados 
com critérios de negócio pelos executivos das áreas solicitantes e beneficiárias do uso de TI.

“Antes, a área de TI era quem de fato preparava a análise de investimento e o defendia perante o Comitê, certamente com o apoio das áreas de negócio, mas com pouco comprometimento destas" (Principal executivo de TI).

Assim, cria-se uma base para o acompanhamento dos gastos com TI e do próprio desempenho da área de TI também com critérios de negócio, garantindo que o vínculo que foi utilizado para a aprovação do investimento original seja utilizado no uso rotineiro dos recursos de TI.

As informações obtidas e disponibilizadas, confirmadas pelos executivos, permite confirmar a proposição 3, sobre a utilização dos vínculos com a análise de investimentos em TI.

\section{Proposição 4: Os Vínculos do Uso de TI com o Desempenho Empresarial Devem Ser Estabelecidos e Utilizados no Gerenciamento de Projetos de TI}

A Estrutura de Benefícios de Tecnologia de Informação no Desempenho Empresarial tem no gerenciamento de projetos de TI uma de suas principais aplicações, sendo que a sua elaboração e a sua utilização podem ser claramente relacionadas com as etapas da metodologia deste tipo de esforço organizacional. A Estrutura foi introduzida com sucesso no gerenciamento dos quatro projetos estudados.

“Agora, além da decisão de aprovar ou não um investimento, temos como analisar as mudanças que ocorrem em cada projeto, se devem ou não ser aceitas" (Executivo de TI).

"Nós passamos a ter melhor noção do efeito de cada decisão do projeto não apenas nele, mas principalmente na contribuição que ele deve dar" (Executivo da área de Vendas).

“Os comitês de projetos passaram a ter base mais confiável para as decisões e ações inerentes ao desenvolvimento destes" (Executivo da área de Engenharia).

"Cada etapa do projeto tem interação com a estrutura de vínculos, seja preparando-a seja utilizando-a, mas sempre como instrumento útil ao bom gerenciamento" (Executivo da área de Infra-estrutura de TI).

"Uma solução de TI deve trazer contribuições para o negócio e isso tem de ser assegurado ao longo do desenvolvimento do projeto" (Executivo da área negócio que interage com a Análise de Negócio). 
A Figura 4 apresenta a inserção das atividades de elaboração e utilização da Estrutura na Metodologia para Gerenciamento de Projetos de TI da Empresa, identificando os pontos onde a Estrutura é aplicada.

\section{Figura 4: Estrutura de Benefícios do Uso de TI no Desempenho Empresarial no Gerenciamento de Projetos de TI}

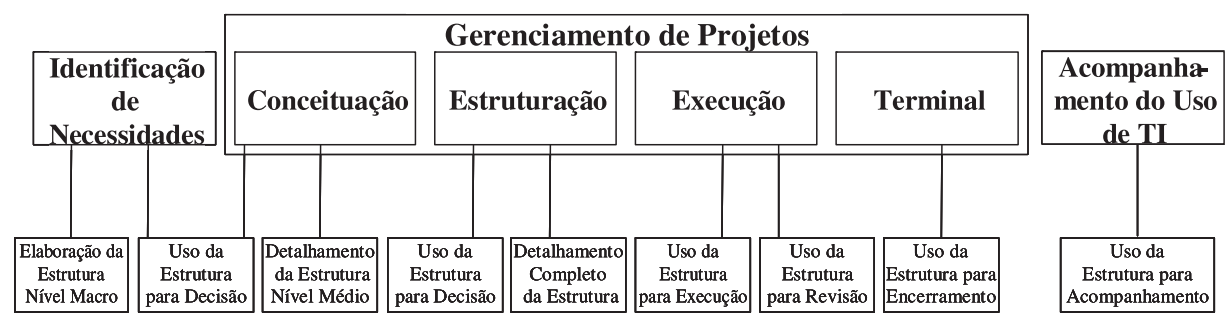

a. Identificação de Necessidades. Nesta fase, realizada para o aproveitamento das oportunidades e resolução de problemas por meio de TI, o contexto é analisado com esta finalidade. Os direcionadores, já apresentados neste documento, são a base para esta análise, em especial o de Tecnologia de Informação, na identificação do uso de TI para as aplicações e infra-estrutura, e Organização, para a identificação dos indicadores de desempenho empresarial, construindo assim a base para o estabelecimento dos vínculos da Estrutura.

a.1. Elaboração da Estrutura - Nível Macro. Esta elaboração, realizada pela área de negócio com apoio da área de TI, com as exceções já comentadas, deve ser no mesmo nível macro que o levantamento das necessidades, ou seja, com uma descrição sumária do uso de TI proposto e sua estimativa inicial de custo, definição da proporção dos benefícios oferecidos, e as principais dimensões do BSC que serão afetadas pelo projeto de TI.

a.2. Uso da Estrutura para Decisão - Gestão de Iniciativas. A Estrutura então compõe a documentação básica para a tomada de decisão do Comitê de Investimentos, que deve garantir o seu uso nesta fase preliminar do projeto.

b. Conceituação. Nesta fase, as informações básicas do projeto de TI são estruturadas visando construir a base de informações necessárias para a tomada de decisão pelo Comitê e para a próxima fase, caso o projeto seja aprovado. Assim, a Estrutura também deve ser detalhada. O desafio desta fase é obter o nível mínimo de informação a ser apresentado ao Comitê, com a máxima alocação de recursos possível, sem que o projeto esteja de fato aprovado. 
b.1. Detalhamento da Estrutura - Nível Médio. A Estrutura deve ter os seus vínculos com os benefícios oferecidos pelo uso de TI e com os indicadores de desempenho empresarial do BSC, estabelecidos num nível que permita a análise completa pelo Comitê. Cabe enfatizar que as áreas que elaboram a Estrutura, geralmente as áreas de negócio, são responsáveis pela sua explicação e justificativa, bem como pelo posterior acompanhamento.

b.2. Uso da Estrutura para Decisão - Iniciação. A Estrutura então compõe a documentação básica para a tomada de decisão do Comitê, que deve garantir o seu uso nesta fase inicial do projeto, analisando somente os projetos que apresentem esta documentação.

c. Estruturação. Nesta fase, as informações do projeto e suas análises são detalhadas até o nível de atividades e recursos específicos, gerando os seus resultados expressos em planos. A Estrutura, de forma similar às demais documentações do projeto, também deve ser revista e detalhada.

c.1. Detalhamento Completo da Estrutura. A Estrutura deve ser completada com as informações obtidas nos demais componentes desta fase, em especial no planejamento de recursos, plano de risco e orçamento dos custos. Ela também deve ser revista com base no detalhamento geral do projeto de TI, confirmando os vínculos com o desempenho empresarial.

c.2. Uso da Estrutura para Decisão - Planejamento. A Estrutura então compõe a documentação básica para a tomada de decisão do Comitê, que deve garantir o seu uso como um dos instrumentos imprescindíveis, nesta fase do projeto que precede a sua execução.

d. Execução. Nesta fase, os planos são executados com a utilização dos recursos do projeto de TI; as atividades devem considerar a Estrutura na realização e elaboração dos resultados que irão garantir a confirmação dos vínculos estabelecidos. Ainda nesta fase, o controle dos desvios, suas justificativas e ações corretivas são analisados e decididos. A Estrutura deve ser analisada e atualizada sempre que necessário.

d.1. Uso da Estrutura para Execução. A Estrutura compõe a documentação básica para as atividades, garantindo que as contribuições do projeto de TI para o desempenho empresarial estão sendo obtidas por meio dos resultados que contribuem para os vínculos estabelecidos.

d.2. Uso da Estrutura para Revisões. A Estrutura compõe a documentação básica para as atividades de revisão como informação, garantindo que as contribuições do projeto de TI para o desempenho empresarial estão sendo obtidas por meio dos vínculos estabelecidos. 
e. Terminal. Nesta fase, o projeto de TI é encerrado, tendo como algumas de suas últimas atividades a avaliação final e a aceitação dos resultados pelos envolvidos. A Estrutura é um dos subsídios para que seja verificado o sucesso do projeto, por meio de verificação do atingimento de seus objetivos, entre eles a confirmação dos benefícios oferecidos pela TI no desempenho empresarial.

e.1. Uso da Estrutura para Encerramento. A Estrutura compõe a documentação básica para as atividades de avaliação final do projeto de TI, para a verificação e confirmação dos vínculos do uso de TI com o desempenho empresarial, e passa a fazer parte integrante da documentação da aplicação em processo ou infra-estrutura. Esta documentação deve ser utilizada no acompanhamento do uso de TI, incluindo os gastos associados ao seu uso rotineiro.

f. Acompanhamento do Uso de TI. O acompanhamento não faz parte do projeto de TI, mas está aqui mencionado para enfatizar a importância das informações do projeto, em especial a Estrutura, para o acompanhamento do uso rotineiro dos produtos e serviços de TI, uma vez que todos os projetos de TI passam a incorporar os gastos de TI após a sua implementação, durante ou após o retorno de seu investimento.

f.1. Uso da Estrutura para Acompanhamento. A Estrutura compõe a documentação básica para o acompanhamento do uso rotineiro dos produtos e serviços de TI, garantindo que as contribuições de TI para o desempenho empresarial estão sendo obtidas por meio dos vínculos estabelecidos.

O estudo do caso da Empresa permitiu estabelecer a relação dos gastos e investimentos em TI com o desempenho empresarial, diretamente com seus indicadores, no caso, os definidos no BSC da Empresa. Isso garante que as decisões sobre estes gastos e investimentos possam ter uma base comum com a gestão da própria Empresa como um todo e de forma integrada, permitindo o acompanhamento dos benefícios oferecidos pelo uso de TI. Em particular, no gerenciamento de projetos, esta relação pode ser utilizada como base para a tomada de decisão, visando atender às expectativas dos solicitantes dos projetos que, de forma geral, é a própria organização, e são expressas nos indicadores de desempenho empresarial.

"Na nossa Empresa, a TI tem papel fundamental que não era expressado de forma totalmente adequada na análise de investimentos nem assegurada satisfatoriamente durante os projetos" (Executivo sênior ao qual o principal executivo de TI responde). 
"Esta nova forma de analisar os investimentos, tomar as decisões nos projetos e acompanhar os gastos com TI, comprometeu ainda mais nossa área, pois passamos a responder diretamente pelos indicadores de negócio em qualquer etapa" (Principal executivo de $\mathrm{TI})$.

A contribuição da utilização da Estrutura no gerenciamento de projetos, confirmada pela percepção dos executivos, permite confirmar a proposição 4 .

\section{Comentários Finais sobre Objetivos, Contribuições, Limitações e Estudos Futuros}

A Estrutura de Benefícios do Uso de Tecnologia de Informação no Desempenho Empresarial foi utilizada com sucesso para a análise e a elaboração das estratégias e operacionalização do uso de TI e de negócio. A Estrutura mostrou-se instrumento fundamental para a administração bem sucedida de TI e para a garantia do aproveitamento dos benefícios do uso de TI no desempenho empresarial, em especial no gerenciamento de projetos de uso desta tecnologia.

O projeto de pesquisa, por meio de estudo de documentos, informações disponíveis e reuniões com os representantes de TI e de negócio da Empresa, estudou os principais usos de TI na Empresa, incluindo projetos, infra-estrutura e demais serviços de TI.

O trabalho permitiu estabelecer a relação do uso de TI com os indicadores de desempenho empresarial da Empresa, nos níveis de empresa, unidade de negócio e da própria área de TI, permitindo comprovar a adequação da Estrutura para as várias etapas do gerenciamento de projetos, ou seja, a identificação de necessidades, o desenvolvimento do próprio projeto e o acompanhamento do uso de TI.

As contribuições incluem:

- Aprimorar o conhecimento da administração de Tecnologia de Informação, em especial na sua relação com os resultados empresariais, permitindo criar uma estrutura de análise dos gastos e investimentos nesta tecnologia nas empresas que ofereça subsídios para a sua administração bem sucedida.

- Aplicar a Estrutura de Benefícios de TI no Desempenho Empresarial, que se destina a ser uma das bases para a administração da função de TI nas organizações.

Uma possível limitação do trabalho é a utilização de uma empresa entre as que mais investem em TI como caso, necessária para garantir uma análise mais profunda e completa do uso de TI num ambiente mais complexo e completo, mas que merece comprovação para as empresas menores e para aquelas que têm uso limitado de TI. 
Outra limitação refere-se à utilização, em parte, da percepção dos executivos, necessária pela falta de dados empíricos mais confiáveis na área de contribuição de TI no desempenho empresarial e que foi tratado adequadamente com o cruzamento de informações e algumas comprovações empíricas, mas permite algum questionamento e merece um estudo futuro de elaboração e comprovação dos indicadores.

Os estudos futuros possíveis são muito promissores e incluem a aplicação do estudo para pequenas empresas e para aquelas que tenham uso restrito de TI.

O estudo futuro que merece destaque refere-se à utilização da Estrutura como base para a identificação das variáveis, indicadores e métricas que estabeleçam e permitam a mensuração do vínculo do uso de TI como o desempenho empresarial, em organizações de outros setores.

\section{Artigo recebido em 09.02.2006. Aprovado em 06.09.2007.}

\section{ReferênCIAS Bibliográficas}

Adams, J. R., \&

Barndt, S. E. (1983).

Behavioral implications of the Project Life Cycle. In D. I. Cleland \& W. R. King (Eds.). Project management handbooks. New York: Van Nostrand Reinhold.

Albertin, A. L. (2004).

Administração de informática: funções e fatores críticos de sucesso (5a ed.). São Paulo: Atlas.

Albertin, A. L., \&

Albertin, R. M. M. (2005).

Tecnologia de informação e desempenho empresarial: as dimensões de seu uso e sua relação com os benefícios de negócio. São Paulo: Atlas.
Amor, D. (2000).

The e-business (R)evolution: living and working in an interconnected world. Upper Saddle River: Prentice Hall.

Bardin, L. (2004).

Análise de conteúdo. Lisboa: Edições 70.

Baschab, J., \&

Piot, J. (2003).

The executive's guide to information technology. New Jersey: John Wiley $\&$ Sons.

Benbasat, I.,

Goldstein, D., \&

Mead, M. (1987).

The case research strategy in studies of information systems. MIS Quarterly, 11(3), 369-387. 
Bonoma, T. V. (1985).

Case research in marketing: opportunities, problems, and a process. Journal of Marketing Research, 22, 199-208.

Christopher, G. (2000).

The valuation of information technology: a guide for strategy development, valuation, and financial planning. Chischester: John Wiley \& Sons.

Devaraj, S., \&

Kohli, R. (2002).

The IT payoff: measuring the business value of information technology investments. New York: Prentice Hall.

Hackett, G. P. (1990).

Investiment in technology: the service sector sinkhole? Sloan Management Review, 31(2), 97-103.

Kanter, R. M. (2001).

Evolve! succeeding in the digital culture of tomorrow. Boston: Harvard Business School.

Kaplan, R. S., \&

Norton, D. P. (1996).

The balanced scorecard: translating strategy into action. Boston: Harvard Business School Press.

Kerzner, H. (1995).

Project management: a systems approach to planning, scheduling, and controlling. New York: McGraw-Hill.

King, W. R., \&

Cleland, D. I. (1983).

Life cycle management. In D. I. Cleland \& W. R. King (Eds.). Project management handbooks. New York: Van Nostrand Reinhold.
Lazzarini, S. G. (1995).

Estudo de caso: aplicabilidade e limitações do método para fins de pesquisa. Economia \& Empresa, 2(4), 17-26.

Lee, A. S. (1989).

A scientific methodology for MIS case studies. MIS Quarterly, 13(1), 45-61.

Leonard-Barton, D. L. (1990).

A dual methodology for case studies: synergistic use of a longitudinal single site with replicated multiples sites. Organization Science, 1(3), 248266.

Mahmood, M. A., \&

Szewczak, E. J. (1999b).

Conclusion measuring information technology investment payoff: a summary. In M. A. Mahmood \& E. J. Szewczak (Eds.). Measuring information technology investment payoff: contemporary approaches. Hershey: Idea Group Publishing.

Mahmood, M. A., \&

Szewczak, E. J. (1999a).

Measuring information technology investment payoff: contemporary approaches. Hershey: Idea Group Publishing.

Markus, M. L., \&

Soh, C. (1993).

Banking on information technology: converting IT spending into firm performance. In R. Banker, R. J. Kaufmann, \& M. A. Mahmood (Eds.). Strategic information technology management: perspectives on organizational growth and competitive advantage. Harrisburg: Idea Group Publishing. 
McKeen, J. D., \&

Smith, H. A. (1993).

The relationship between information technology use and organizational performance. In R. Banker, R. J. Kaufmann, \& M. A. Mahmood (Eds.). Strategic information technology management: perspectives on organizational growth and competitive advantage. Harrisburg: Idea Group Publishing.

McKeen, J. D.,

Smith H. A., \&

Parent, M. (1999).

An integrative research approach to assess the business value of information technology. In M. A. Mahmood \& E. J.Szewczak (Eds.). Measuring information technology investment payoff: contemporary approaches. Hershey: Idea Group Publishing.

Means, G., \&

Schneider, D. (2000).

Meta-capitalism: the e-business revolution and the design of 21 st century companies and markets. New York: John Wiley \& Sons.

Morton, M. S. S. (Org.). (1991).

The corporation of the 1990s: Information Technology and organizational transformation. Oxford: Oxford Press.

Murphy, T. (2002).

Achieving business value from technology: a practical guide for today's executive. New Jersey: John Wiley \& Sons.
Pinto, J. K., \&

Slevin, D. P. (1988).

Critical success factors across the project life cycle. Project Management Journal, 19(1), 69-74.

Project Management Institute. (1998).

A guide to the project management body of knowledge. UpperDarby: Author.

Remenyi, D.,

Money, A., \&

Sherwood-Smith, M. (2000).

The effective measurement and management of it costs and benefits. Oxford: Butterworth-Heinemann.

Sampler, J. L. (1998).

Exploring the relationship between information technology and organization structure. In M. J. Earl (Org.). Information managment: the organization dimension. New York: Oxford University Press.

Schein, E. H. (1989).

The role of the CEO to the management of change: the case of information technology [Working Paper No 89-075]. Cambridge, MIT, Sloan School of Management. Cambridge, MA, USA.

Schiffrin, D. (2001).

The Handbook of discourse analysis. Oxford: Blackwell

Slack, N.,

Chambers, S., \&

Johnston, R. (2000).

Operations Management. New York: Prentice Hall. 
Tardugno, A. F.,

Dipasquale, T. R., \&

Matthews, R. E. (2000).

IT services: costs, metrics, benchmarking, and marketing. New Jersey: Prentice Hall.

Towell, E. R. (1999).

Business use of the internet. In M. A. Mahmood \& E. J. Szewczak (Eds.). Measuring information technology investment payoff: contemporary approaches. Hershey: Idea Group Publishing.

Trice, A. W., \&

Treacy, M. E. (1986).

Utilization as a dependent variable in

MIS research. Proceedings of Seventh International Conference on Information Systems, San Diego, CA, USA, 7 .

Veen-Dirks, P. van, \&

Wijn, M. (2002).

Strategic control: meshing strategic control: meshing critical success factors with the balanced scorecard. Long Range Planning, 35(4), 407-427.

Venkatraman, N. (1989).

Strategic orientation of business enterprises: the construct, dimensionality, and measurement. Management Science, 3(8), 942-962.

Venkatraman, N. (1991).

IT-induced business reconfiguration. In M. S. S. Morton (Org.). The corporations of the 1990s: information technology and organizational transformation. Oxford: Oxford University Press.

Weill, P., \&

Broadlent, M. (1998).

Leavering the new infrastruture: how market leaders capitalize on IT. Boston: Harvard Business Scholl Press.

Weill, P., \&

Vitale, M. R. (2001).

Place to space: migrating to ebusiness models. Boston: Harvard Business Scholl Press.

Wodak, R. (2001).

Methods of critical discourse analysis. London: Sage.

Yin, R. K. (1994).

Case study research: design and methods. Newburry Park: Sage Publications. 